Skiagram shows enlargement of sella turcica in antero-posterior diameter; depth about average. Anterior elinoid processes undermined ; posterior clinoid processes look partly effaced.

Cranial nerves (apart from optic) normal. Speech normal. Motor power, co-ordination and sensation good. Arm and abdominal reflexes good. Knee-jerks exaggerated. Left ankle clonus; none right. Plantar reflex not obtained. No sphincter trouble. Chest nil.

The case was thought to be one of hypopituitarism, which may possibly depend on destruction of the pituitary body by a crstic growth.

\title{
Archer Ryland.
}

Herpes Zoster of the Glosso-pharyngeal Nerve.-C. T. Neve. "Brit. Med. Journ.." November 15, 1919.

Two days after a long and cold motor journey, Miss M-, aged fifty-seven, complained of vomiting and malaise, of deafness in the left ear, and of pain behind the left ear and in the left side of the neck.

The temperature was $100^{\circ} \mathrm{F}$., the left facial nerve was paralysed, and there was a herpetiform eruption on the left side of the soft palate. The left tympanic membrane was of normal appearance and the skin of the auricle was unaltered, though the acoumeter was heard at 2 in. only.

All the symptoms passed off within ten days.

The writer suggests that the lesion on the palate was due to a lesion of the ninth nerve ganglion, that the pain behind the ear and the vomiting resulted from involvement of the tenth nerve ganglion, and that the pains in the neck indicated lesions of the second and third cervical ganglia. The picture, therefore, was that of a posterior poliomyelitis of the ganglia of the seventh, eighth, ninth and tenth cranial nerves, and of the second and third cervical nerves, the infection being most acute in the upper ganglia. In support of this contention the views of Ramsay Hunt are quoted. Hunt did not describe any cases in which he found evidence of herpetic inflammation of the glosso-pharyngeal ganglion, though he mentions the possibility of its occurrence. He had one case of herpes auricularis in which stiffness of the neck, frequent vomiting and slow, irregular pulse indicated that the vagus might be involved.

Douglas Guthrie.

\section{NOTES AND QUERIES.}

Sir James Dundas-Grant, K.B.E.

Among the recipients of the recent Birthday Honours we are interested and pleased to observe the name of Dr. J. Dundas Grant, who, for notable and highly successful services in connection with the treatment of ear disease in pensioners, has received a Knighthood of the British Empire.

Readers of this Journal, which for many years he edited, vill, we are sure, be pleased to unite with us in offering to Sir James Dundas-Grant our warmest congratulations upon a well-deserved honour.

Soctéte Belge d'Otologie, de Rhinologie mi di Laryngologie.

The Twenty-sixth Annual Congress of this Society will be held in Brussels on July 10-12.

The general discussions will be on (1) Diphtheria and its complications, and on (2) The operative treatment of laryngo-tracheal stenoses of diphtheritic origin. There will be a demonstration of patients, specimens and instruments.

On July 12 there will be an excursion to the Domaine de Mariemont and the rich collections of the Fondation Warocqué.

The President of the Congress is Dr. Ernest Delstanche, and the Secretary General is Dr. A. Capart fils, rue d'Egmont 5, Bruxelles. 
NOW READY. 38th YEAR OF ISSUE.

Fully Illustrated in Colours and Black and White. Price 20/- net.

MEDICAL ANNUAL, 1920. A YEAR-BOOK OF TREATMENT,
AND PRACTITIONER'S INDEX:

Being a Review of the World's Progress in Medicine and Surgery. Arranged in Alphabetical Order for Easy Consultatiox.

\section{Contributors :}

SURG. JOHN A. M. ALCOCK, R.N.

E. WYLI,YS ANDREWS, F.A.C.S., A.M., M. D., Chicago. JOSEPH BLOMFIELD, O.B.E., B.A., M.D. FRANCIS J. CHARTERIS, M.D., B.CH. JOHN D. COMRIE, M.A., M.D., F.R.C.P. CAREY F. COOMBS, M.D., F.R.C.P.

W. E. FOTHERGILL, M.A., M.D. JOHN S. FRASER, M.B., CH.B., F.R.C.S. HERBERT FRENCH, M.A., M.D., F.R.C.P. OSKAR C. GRUNER, M.D.

COL. LAWRENCE W. HARRISON, D.S.o., R.A.M.C. C. THURSTAN HOLLAND, M.R.C.S., L. R.C.r. J. RAMSAY HUN'T, M.D., New York. ROBERT HUTCHISON, M.D., F.R.C.P. FREDERICK LANGMEAD, M.D., F.R.C.P. ARTHUR LATHAM, M.A., M.D., F.R.c.P. E. G. GRAHAM LITTI,E, M. D., F.R.C.P.
J. P. LOCKHART-MUMMERY, M.B., F.R.C.S. R. FOSTER MOORE, O.B.E., M.A., B.C., F.R.G. MAURICE NICOLL, B.A., M.B., B.C., M.R.C.s. BEDFORD PIERCE, M.D., F.R.C.P. JOSEPH PRIESTLEY, B.A., M.D., D.P.h. Sir LEONARD ROGERS, C.I.E., Lt.-Col. I.M.S., M.D, F.R.C.P., F.R.C.S., Calcutta.

J. D. ROLLESTON, M. A., M.D.

A. RENDLE SHORT, M.D., B.S., F.R.C.s. GEORGE A. SUTHERLAND, M.D., F.R.C.P. J. W: 'THOMSON WALKER, F.R.C.S. ALBERT J. WALTON, M.s., F.R.C.S. P. WATSON-WILLIAMS, M.D., M.R.C.S. SIR W. I. DE COURCY WHEELLR, F.R.C.S. MARGUERITE WILSON, $\mathrm{N}_{\mathbf{3}} \mathrm{B}_{\text {, }}$ сн.B. ANDREW J. M. WRIGHT, M.B., F.R.C.S.

(Medicine) CAREY F. COOMBS, M.D., F.R.c.P. ; (Surgery) A. RENDLE SHORT, M.D., B.5., F.R.c.s.

The bulk of this volume has already been subscribed and delivered. To avoid disappointment, early application is advised.

\section{From the Preface.}

"The volume shows that our profession has not suffered from that form of malaise which seeks relief in longer hours of leisure. There is hardly a paragraph which is not the result of work accomplished after the day's routine has been completed. It is only in this way we can make those investigations which lead to the more efficient relief of suffering."

\section{From Press Notices.}

British Medical Joumal. - "Good reading, and an excellent investment."

Lancet.- "A valuable addition to the library of the Medical Practitioner; contains in one volume a practical summary of the progress of medicine during the past year."

\section{BRISTOL: JOHN WRIGHT \& SONS LTD. LONDON: SIMPKIN, MARSHALL \& CO. LTD.}




\section{A NEW HEAD LAMP.}

Devised by GILBERT CHUBB, M.B., D.Sc.Lond., F.R.C.S. Eng.
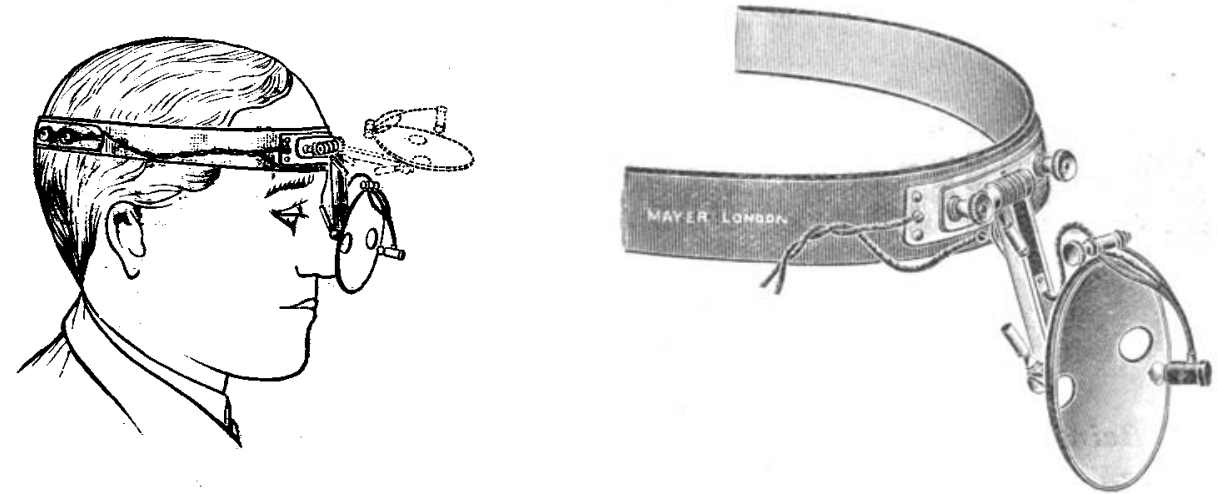

An improved lamp on the Klar principle; fitted with unbreakable mirror of speculum metal; easily adjusted and economical in use. (Vide Lancet, March $13^{\text {th }}$, 1920.)

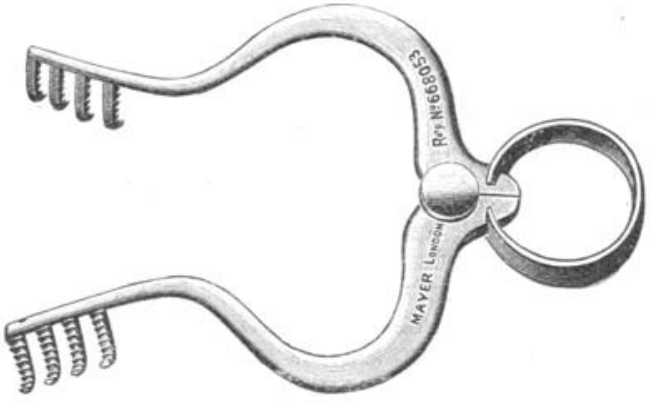

\section{A MASTOID RETRACTOR}

Designed by B. SEHMOUR JOKES, F.R.C.S., Surgeon, Birmingham Ear and Throat Hospital.

A simple self-retaining spring retractor; easily placed in position and removed and not liable to slip when in use.

\section{A TONGUE HOLDER \& DEPRESSOR for Tonsillectomy. Suggested by JAMES DONELAN, Ch.M.. M.B.}

When removing the tonsils by dissection this tongue forceps has been found useful. The points are inserted transversely and well back in the dorsum of the tongue, which is depressed so as to give a good view and free the respiratory passages.

Particulars an application to
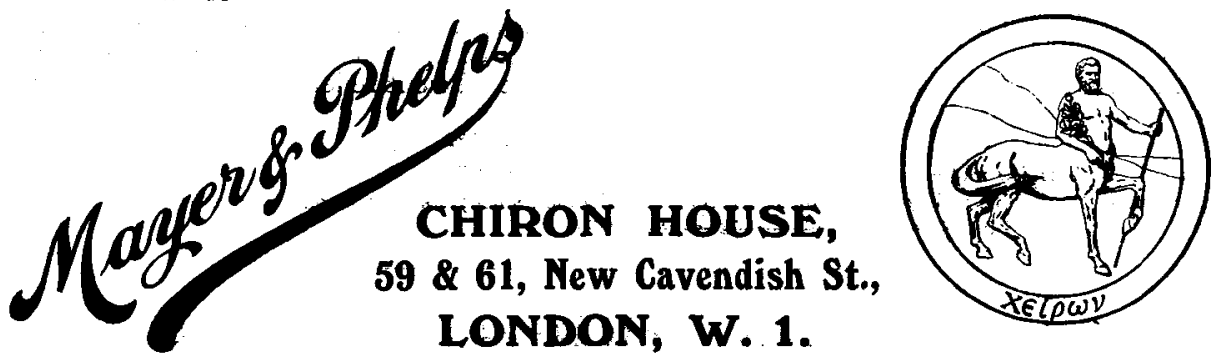

Telephone:

MAYFAIR 6320 (2 lines).

Telegrams:

"TREPHINE, WESDÓ, LONDON." 

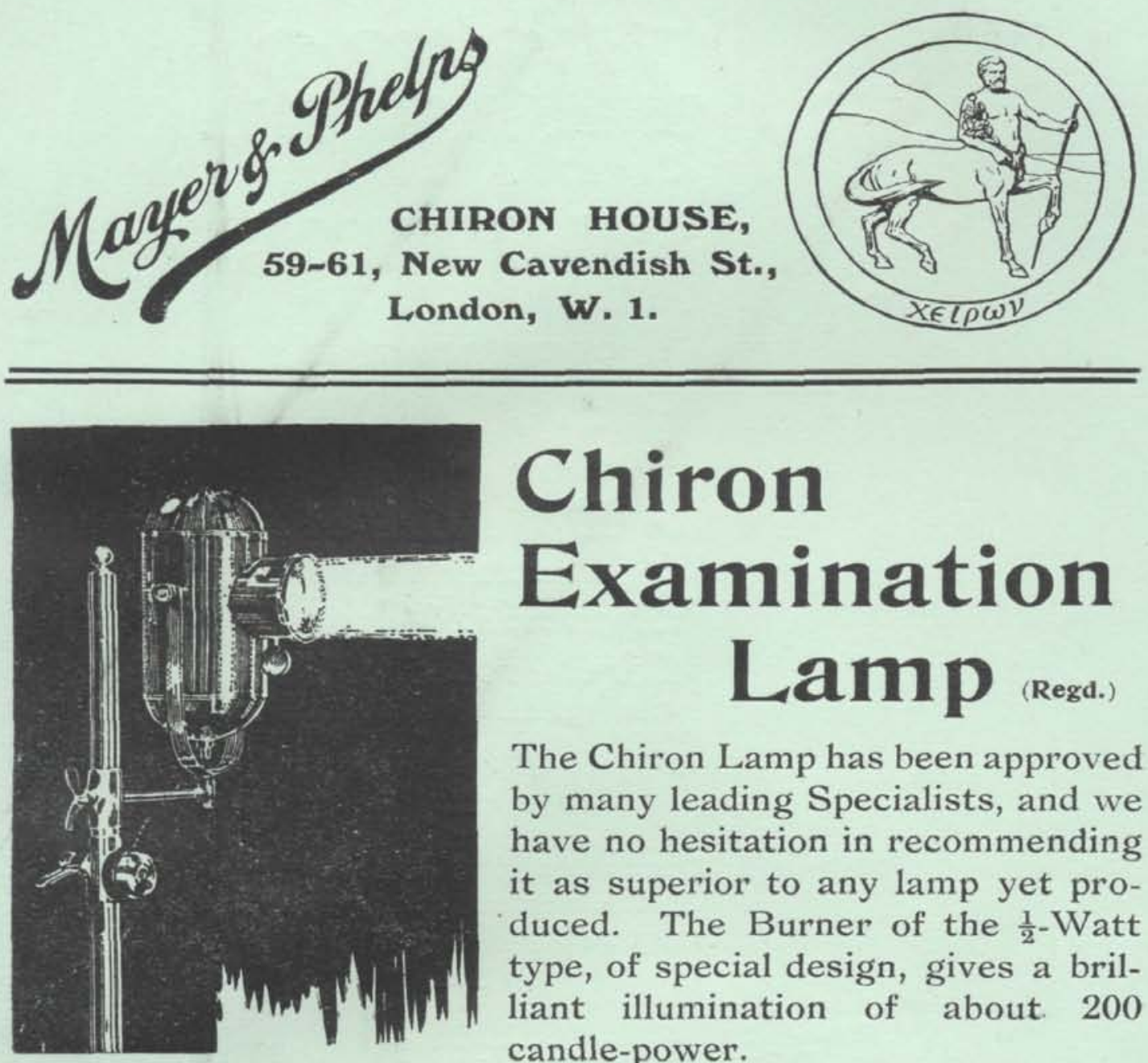

\section{Chiron Examination Lamp}

The Chiron Lamp has been approved by many leading Specialists, and we have no hesitation in recommending it as superior to any lamp yet produced. The Burner of the $\frac{1}{2}$-Watt type, of special design, gives a brilliant illumination of about 200 candle-power.

\section{TONSIL PASTE APPLICATOR.}

Devised by IRWIN MOORE, M.B., C.M.Edin., Surgeon to the Throat Hospital, Gelden Square.
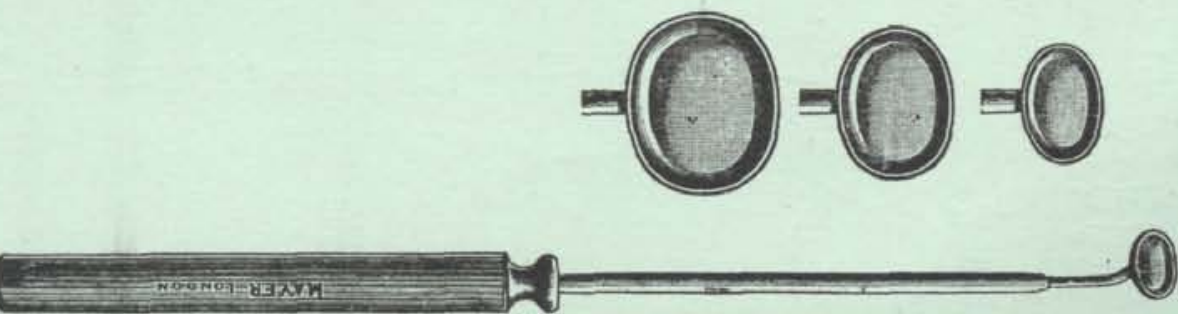

Vide "The Treatment of Enlarged or Diseased Tonsils in Cases where Surgical Procedures are Contra-indicated" (Fournal of Laryngology, October, 1919). 


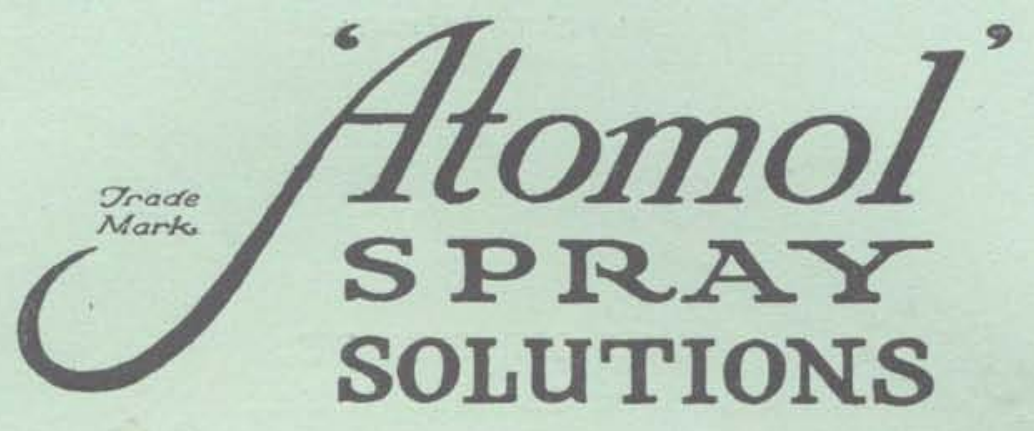

A comprehensive 리레.||||||||||||||||||| series for the treatment of Acute of Chronic Rhinition, Bronchial Catarrh, Chronic Laryngitis. Influenzal Catark. - etc.

Brochure giving the formula of the series sent free on request.

||||||||||||||||||뜬

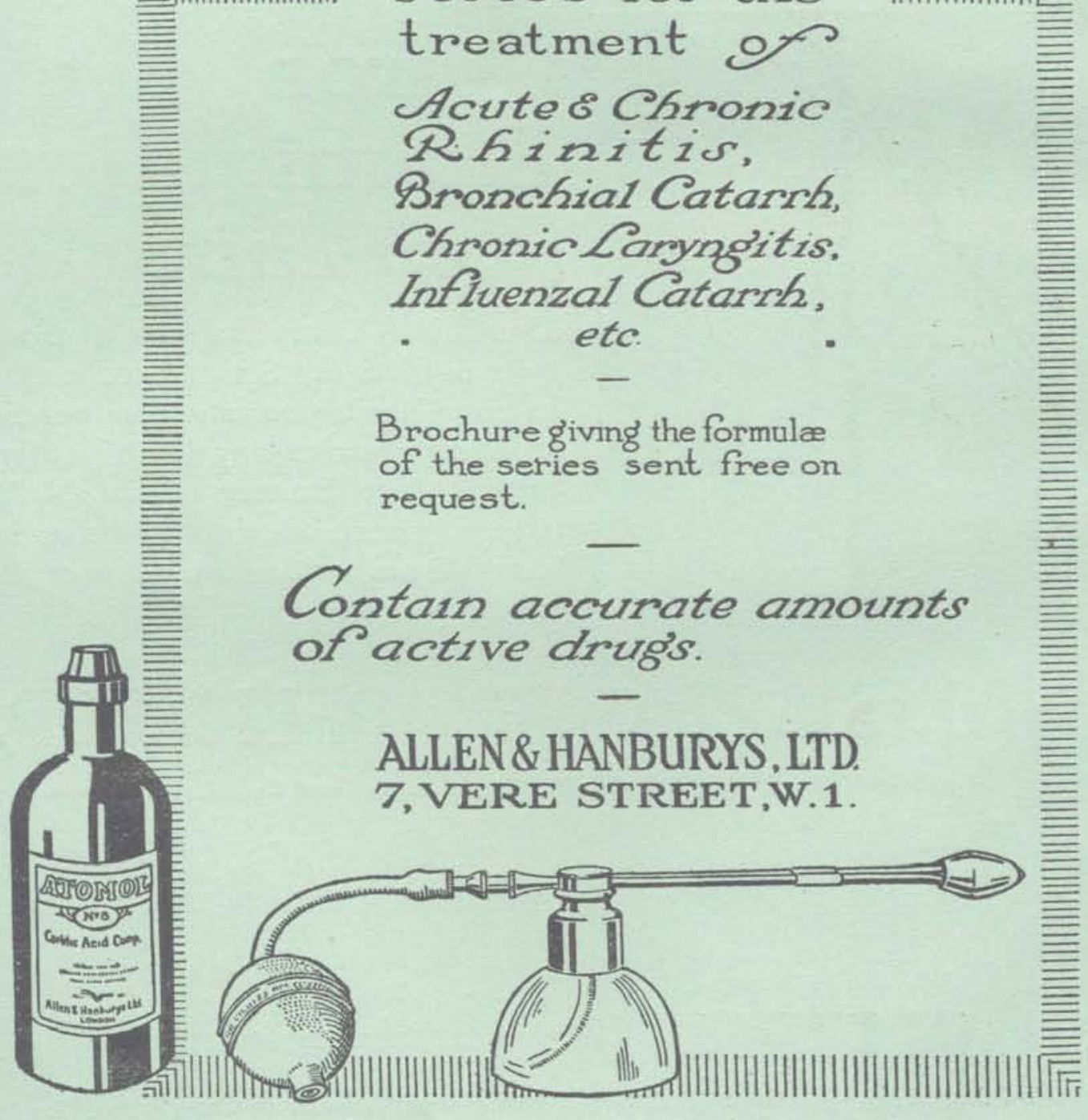

